\title{
Contributions of dynamic environmental signals during life-cycle transitions to early life-history traits in lodgepole pine (Pinus contorta Dougl.)
}

\author{
Yang Liu, Tongli Wang, and Yousry A. El-Kassaby \\ Department of Forest and Conservation Sciences, University of British Columbia, 2424 Main Mall, Vancouver, \\ British Columbia V6T 1Z4, Canada \\ Correspondence to: Yousry A. El-Kassaby (y.el-kassaby@ubc.ca)
}

Received: 22 July 2015 - Published in Biogeosciences Discuss.: 27 August 2015

Revised: 19 April 2016 - Accepted: 3 May 2016 - Published: 19 May 2016

\begin{abstract}
Environmental signals are important triggers in the life-cycle transitions and play a crucial role in the life-history evolution. Yet very little is known about the leading ecological factors contributing to the variations of life-history traits in perennial plants. This paper explores both the causes and consequences for the evolution of life-history traits (i.e., seed dormancy and size) in lodgepole pine (Pinus contorta Dougl.) across British Columbia (B.C.), Canada. We selected 83 logepole pine populations covering 22 ecosystem zones of B.C. and through their geographic coordinate, 197 climatic variables were generated accordingly for the reference (1961-1990) and future (2041-2070) periods. We found that dynamic climatic variables rather than constant geographic variables are the true environmental driving forces in seed dormancy and size variations and thus provide reliable predictors in response to global climate change. Evapotranspiration and precipitation in the plant-to-seed chronology are the most critical climate variables for seed dormancy and size variations, respectively. Hence, we predicted that levels of seed dormancy in lodgepole pine would increase across large tracts of B.C. in 2050s. Winter-chilling is able to increase the magnitude of life-history plasticity and lower the bet-hedge strategy in the seed-to-plant transition; however, winter-chilling is likely to be insufficient in the north of $49^{\circ} \mathrm{N}$ in 2050 s, which may delay germination while unfavorable conditions during dry summers may result in adverse consequences in the survival of seedlings owing to extended germination span. These findings provide useful information to studies related to assessments of seed transfer and tree adaptation.
\end{abstract}

\section{Introduction}

In the context of global climate change, species have responded by tracking the environment for which they are best suited through local adaptation, range shift, range reduction, or a combination of these (Walther et al., 2002; Parmesan and Yohe, 2003; Cleland et al., 2007; Breshears et al., 2008). Knowledge about traits that vary with ecological niches should therefore help predict how these traits may evolve under climate change. Life-history traits, known as fitness components due to predictable monotonic relationship with fitness, are related to the timing and success of development, reproduction, and senescence throughout the life cycle (Calow, 1998). Ecological and genetic trade-offs constrain the combinations of the life-history traits through evolution (Adler et al., 2014), which involves an adaptation to environments and is shaped by natural selection.

Climate change has already altered the timing of major life-history transitions, such as seed germination timing (from seed to plant). Timing is directional and completely asymmetric and the timing of seed germination is the earliest life-history trait that is expressed and sets the context for the traits that follow (Donohue et al., 2010). It is controlled by the level of seed dormancy, whereby dormant seeds await germination cues for dormancy release (Finch-Savage and Leubner-Metzger, 2006; Baskin and Baskin, 1998). Moreover, early developmental stages of plants are more sensitive to environment perturbations than adult stages and represent a major bottleneck to regeneration from seeds (Johnsen and Skrøppa, 1996; Hedhly et al., 2009). At the core of plant regeneration, temperature and water availability (or precipita- 
tion) are critical drivers for a plant's distribution (Woodward and Williams, 1987). Hence, climate-changed plant regeneration will be manipulated in both temperature- and moisturecontrolled ecosystems (Walter and Breckle, 2002) and a lot of plant regeneration climate research has been directed at tundra and boreal forest, and treeline ecotones (reviewed in Walck et al., 2011).

Seed size is another important life-history trait and subject to changing environmental settings. In the palaeontological scale, fossil data suggest that seed size remains small across all plants until the Cretaceous period (124 MYA). Seed size begins to increase after the limit of the CretaceousTertiary period (65 MYA). One of the most popular explanations is that climate change gives rise to seed size variation, which took place during that period (Eriksson et al., 2000). In the ecological timescale, empirical studies lend supports to the impact of environment on seed size variation. Since the early 1950s, effects of environmental stimuli, such as temperature and photoperiod on seed size and weight have been noted. Chenopodium polyspermum $\mathrm{L}$. seeds from mother plants grown in long days have lower germination frequency and thicker seed coats when compared to seeds from short days (Pourrat and Jacques, 1975). Large seed size with more provisions stored for seedlings may be favorable in variable environments (Venable and Brown, 1988). Seed plants have a general trend of increasing embryo to seed ratio $(E: S)$ in morphological seed dormancy and the shift in $E: S$ is likely a heterochronic change, having vital implications to life history of seed plants (Forbis et al., 2002). A priori, the environment plays a crucial role in life-history traits in general and seed size in particular.

Adaptive phenotypic plasticity underpins rapid phenological shifts in response to climate change and evolves when cues reliably predict fitness consequences of life-history decision (Simons, 2014). This was evident by the performance of seedlings produced by central European trees growing in central Norway as they expressed phenology similar to that of their adjacent ecotype and were exceedingly different from those produced at their original habitat (Skrøppa et al., 2010). Differences in adaptive traits between populations are inconsistent with the Mendelian genetic framework and probably modulated by epigenetic mechanisms (Yakovlev et al., 2012). Germination-cuing under favorable conditions is similar within species; however, these conditions do not persist throughout the seasons. Likewise, populations growing in different ecological niches may have different degrees of exposure to unfavorable environments. As such, the prevention of germination of some seeds even under favorable conditions would be of significance. When environments fluctuate unpredictably, "bet-hedging" strategy (Slatkin, 1974) is expected to spread germination over time to reduce the risk of outright extinction. This results in the evolution of traits that maximizes the geometric-mean fitness by reducing fitness variance over generations (Gillespie, 1977). To date, much of the evidence for bet-hedging remains restricted to simple life-history plants (e.g., annuals; Childs et al., 2010).

A continuously changing environment is constantly selecting for new adapted genotypes resulting in greater genetic diversity (Jump et al., 2009). Adaptive evolution characterized by the genetic architecture allows population persistence in the long term (Lande and Shannon, 1996). However, sustained directional selection due to climate change could potentially eliminate a proportion of the genetic variation needed for continued adaptation. To date, it remains unclear whether adaptive evolution can keep pace with climate change (Etterson and Shaw, 2001).

Life-history strategy for long-lived organisms is influenced primarily by survival (Adler et al., 2014). Evergreen coniferous forests in the Pacific Northwest are unique among the Northern Hemisphere temperate forests in their species composition and high productivity (Waring and Franklin, 1979). Our study species, lodgepole pine (Pinus contorta Dougl.), is an aggressive pioneer species distributed over wide geographic and ecologic ranges across British Columbia, Canada and is therefore expected to display a wide spectrum of dormancy variation owing to adaptation to diversified local habitats (Plomion et al., 2007). Cone and seed production in lodgepole pine is not as cyclic as in many other conifers. Cone drop soon after seed maturation is commonly observed in coastal areas but lodgepole pine growing in the interior tends to be serotinous, indicating that mature cones do not drop or open to release seeds unless exposed to fluctuating high temperature during a prolonged hot summer and low autumn temperatures or due to fire or insect damage (Fowells, 1965; Owens et al., 1981, 1982). Most serotinous cones take several years to open and seeds are released in large quantities, consequently, any seed collection made from a single tree consists of a mixture of different seed-crop years. Before the cones eventually open, seeds are wrapped and sealed by scales and sticky resin without exposure to any germination cues (such as moisture, oxygen, etc.); thus we assumed that seed dormancy in lodgepole pine is least affected over its natural storage period.

Seed dormancy is an intrinsic attribute affecting regeneration dynamics and seed size is one of the vital determinants for the evolution of seed dormancy. The objectives of this study are to evaluate the contributions of local environmental effects during life-cycle transitions to seed dormancy and size variations of lodgepole pine populations across British Columbia, Canada and to predict how lifehistory traits evolve locally under ongoing climate change. Studies of seed dormancy and size allow us to investigate the relationship between these two life-history traits and their relationship with environments in life-cycle transitions. This study can also contribute to providing the missing empirical evidence of bet-hedging strategy in long life-history plants. 


\section{Methods}

\subsection{Plant materials, and current and future climate data}

The 83 lodgepole pine seed lots used were representative of 83 different populations covering 22 ecosystem zones. The seed lots are distributed throughout the species' natural range across British Columbia (B.C.), Canada, encompassing coastal area and interior regions with a spatial grid over a latitudinal range from 49 to $60^{\circ} \mathrm{N}$ and longitudinal range from 115 to $132^{\circ} \mathrm{W}$, which consist of tundra, boreal and temperate forests, and treeline ecotone ecosystems (Fig. S1 in the Supplement). The studied populations were selected primarily based on two important climate variables; namely, mean annual temperature (MAT) and annual heat moisture index (AHM; Fig. S2; Wang et al., 2006) and geographic variables, including longitude, latitude, and elevation were also considered.

Climate data (197 climatic variables) of the 83 studied sites for the reference normal period 1961-1990 were generated using ClimateWNA version 4.85 (a software package used for regional climate predictions using historical weather station data and global circulation models; Wang et al., 2012). The same 197 climatic variables for the future period between 2041 and 2070 (or 2050s) were also projected using ClimateWNA. The future climate data were downscaled to point locations using a delta approach (Wang et al., 2012). We used three representative concentration pathways (RCP) 2.6, 4.5 and 8.5 from the CGCM4 model output of the phase 5 of the Coupled Model Intercomparison Project (CMIP5), generated by the United States National Center for Atmospheric Research. The CCSM4 model output was included in the Intergovernmental Panel on Climate Change (IPCC) Fifth Assessment Report (AR5; Stocker et al., 2013). Moreover, CCSM4 is close to the average in both temperature and precipitation increases in the study areas (B.C.). In the prediction of seed dormancy indicators across B.C. for the reference period and 2050s, climate data were generated for each pixel at the spatial resolution of $800 \times 800 \mathrm{~m}$ using ClimateWNA. The full list of climatic variables is given in Table $\mathrm{S} 1$ in the Supplement and the four most relevant variables for the present study were Eref07 and _summer (July and summer hargreaves reference evaporation estimated based on temperature and solar radiation), DD_O_summer (summer degree-days below $0{ }^{\circ} \mathrm{C}$ ), PPTO7 and 10 (July and October precipitation; $\mathrm{mm}$ ), and Tmax07 (July maximum mean temperature; $\left.{ }^{\circ} \mathrm{C}\right)$.

\subsection{Life-history traits' measurement}

Germination parameters were estimated from cumulative germination curves fitting a mathematical function known as the four-parameter Hill function (El-Kassaby et al., 2008). Core germination parameters include dormancy index (DI, the difference of areas under germination curves (AUC) of control and treated seed), germination capacity (GC, the final germination fraction), time to germination (time at the onset of germination), and germination speed (GS, the time required to achieve $50 \%$ germination of the total germinated seed; graphically represented by Fig. S3, Liu and ElKassaby, 2015). To simulate winter chilling in the soil seed bank and retain natural seed dormancy, seed germination was manipulated with or without 21-day moist-chilling treatment under $3{ }^{\circ} \mathrm{C}$ in lightproof chamber. Germination assay was performed as previously described (Y. Liu et al., 2013) and seed size was measured as the average of 1000-seed weight collected from each study site.

\subsection{Data analysis and visualization}

To investigate which climatic variables can most explain the observed patterns of seed dormancy and size variations, partial least squares (PLS) analyses were conducted using SAS ${ }^{\circledR}$ (vers. 9.3; SAS Institute Inc., Cary, NC; Crossa et al., 2013). The goal of PLS regression is to analyze multivariate response based on a large set of explanatory variables (i.e., climatic variables). This technique combines features from principle component analysis (PCA) and multiple regression (Abdi, 2007; Carrascal et al., 2009). PLS regression is particularly suitable when the matrix of predictors has more variables than observations, and when there is multicollinearity among $\mathrm{N}$ values. Using the machine-learning algorithm (i.e., PLS), important climate variables can be identified through a process of model optimization and there is no need to explain the contribution of climate variables in the initial input data set. In the PLS biplot, the angles between the environment vectors approximately correspond to the correlation coefficients among the environments. The cosine of the angle between two vectors approximates the correlation between them, and the length of the vectors is proportional to the standard deviation within respective environments or genotypes (Yan, 2001; Yan and Tinker, 2006). Virtually, an ideal environment has the longest vector of all test environments (most discriminating and informative) and is closely located on the abscissa (most representative; Liu and El-Kassaby, 2015). As a comparison, PCA for explanatory variables and canonical correlation analysis (CCA) dealing with both explanatory and response variables were also performed (Liu and El-Kassaby, 2015). To examine how seed dormancy and size varied in ecosystem zones, the two variables were analyzed collectively using multivariate analyses (MANOVA) with the aid of general linear model (GLM) procedure in SAS (Manly, 2005; Tabachnick and Fidell, 2012). To investigate how the most correlated climatic and geographic variables affect life-history traits, hierarchical models were established using PROC MIXED in SAS with errors split into population and ecosystem zones but having unequal variances at the population level (West et al., 2007; Raudenbush and Bryk, 2001). The most correlated climatic variables through the 
PLS analysis were used and the model was expressed as follows:

$$
\begin{aligned}
(\text { life-history trait })_{i j} & =\left(\beta_{0}+\varepsilon_{j}\right)+\beta_{k} \times P_{k i j} \\
& +\beta_{l} \times T_{l i j}+\varepsilon_{i j}
\end{aligned}
$$

where $i$ and $j$ represent two levels, namely, $i$ th population within $j$ th ecosystem zone; $P_{k i j}$ and $T_{l i j}$ represent the $k$ th precipitation- and $l$ th temperature-based variable in $i$ th population within $j$ th ecosystem zone, respectively; $\varepsilon_{j}$ and $\varepsilon_{i j}$ represent errors from the ecosystem zone and population level, respectively. Intercept $\left(\beta_{0}+\varepsilon_{j}\right)$ and coefficients $\left(\beta_{k}\right.$ and $\left.\beta_{l}(k, l=1,2,3, \ldots)\right)$ were estimated using our experiment data. Analogously, fitting models using longitude, elevation, and latitude as independent variables were established. Using the foregoing climatic model for the reference period and 2050s via CCSM4 RCP 4.5, DI values were estimated for each pixel across $\mathrm{BC}$ at the resolution of $800 \times 800 \mathrm{~m}$ and mapped across B.C. for visualization.

To investigate the phenotypic plasticity of timing of seed germination, Pearson's product-moment correlation was calculated. The mean phenotypic plasticity of timing of seed germination is the magnitude of the average response of the population genotypes to specific environments and calculated as a population's mean AUC in the chilling manipulation minus its corresponding value in the control (i.e., DI). To investigate the range of possible plastic response to dormancy and to determine its genetic contribution to the phenotypic variance, the following linear model was used:

$\mathrm{DI}_{i j}=\mu+G_{i}+E_{j}+\mathrm{GE}_{i j}+\varepsilon$,

where $\mathrm{DI}_{i j}$ is dormancy index of $i$ th genotype in $j$ th environment, $\mu$ is the overall mean, $G_{i}$ is the effect of the $i$ th genotype, $E_{j}$ is the effect of the $j$ th environment, $\mathrm{GE}_{i j}$ is the interaction of $i$ th genotype with $j$ th environment, and $\varepsilon$ is the random error. The range of phenotypic plasticity is interpreted as $G \times E$ variation $\left(V_{G \times E}\right)$ and the extent of genetic control of a trait was calculated by broad-sense heritability $\left(H^{2}=V_{G} /\left(V_{G}+V_{G \times E}+V_{\varepsilon}\right)\right)$.

To evaluate bet-hedge strategy in seed germination, two potential traits were tested, i.e., germination capacity and time to germination. Specifically, germination capacity was the subject of Cohen's classic bet-hedging model (Cohen, 1966), in which dormancy is expected to evolve in proportion to the probability of encountering a "bad" year, which corresponds to no chilling manipulation in this study. Time to germination in a "bad" or "good" year (i.e., no chilling vs. chilling) represents within-season variation, which has been shown to be advantageous when germination success is unpredicted within season (Simons, 2009). The standard deviation (SD) for these two traits in a "good" and "bad" year was also calculated to measure the amount of variation across studied populations.
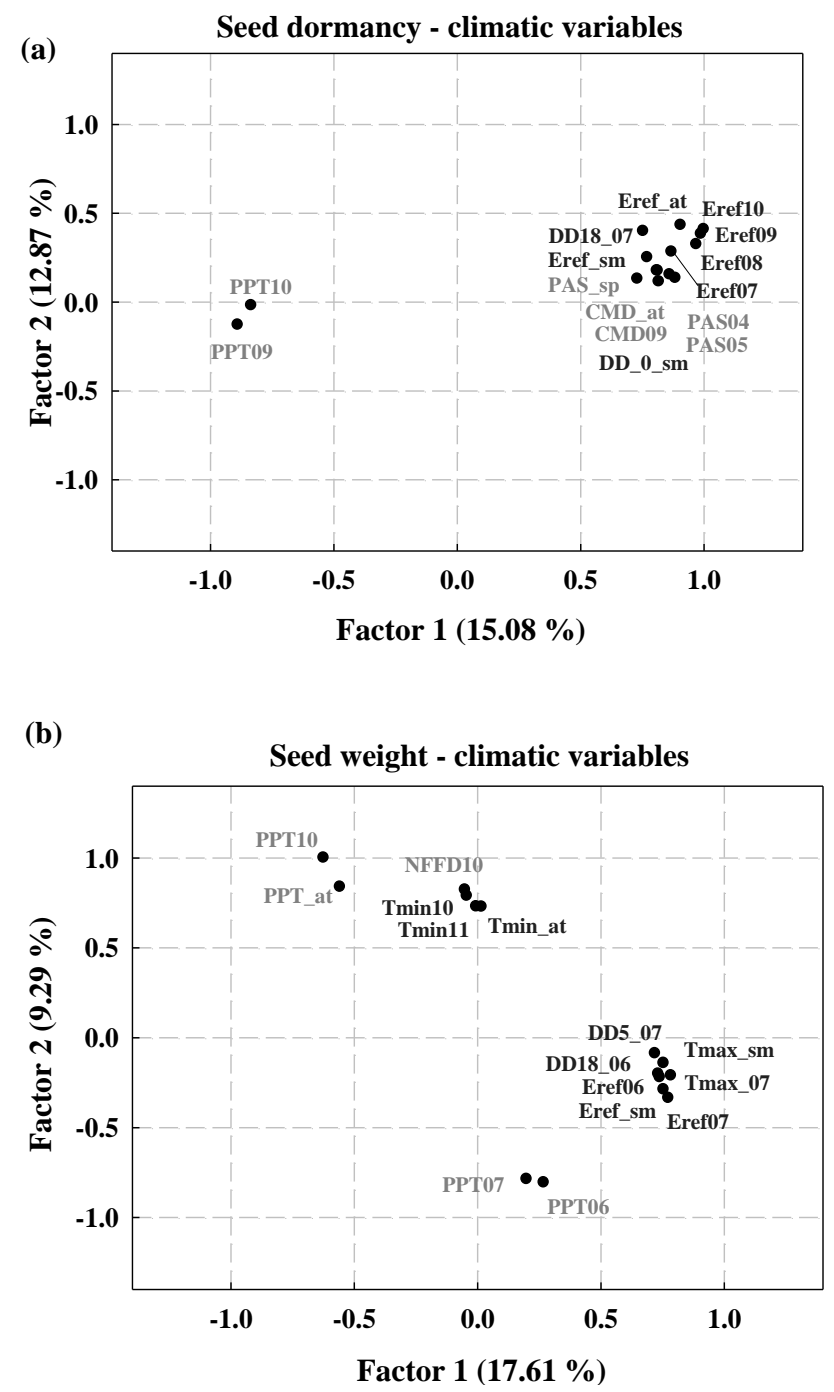

Figure 1. The 15 most correlated climatic variables with seed dormancy (a) and size (b) after partial least squares (PLS) regression. Note: (1) three variables (Eref07 and_summer, and PPT10) were highly correlated with both seed dormancy and size; (2) fonts in black and grey represent the temperature- and precipitation-based climatic variables, respectively; (3) see Table S1 for full names of abbreviated variables.

\section{Results}

\subsection{Life-history traits strongly correlated with climatic variables in the plant-to-seed transition}

Partial least squares (PLS) analyses for seed dormancy and weight indicated that the first and second components accounted for 15 and 13 , and 18 and $9 \%$ of the total variation, respectively (Fig. S4). The 15 most correlated climatic variables with respect to life-history traits were correlated with environmental factors related to temperature (Fig. 1). This indicates that temperature plays a major role in the development of life-history traits (Liu and El-Kassaby, 2015). By 

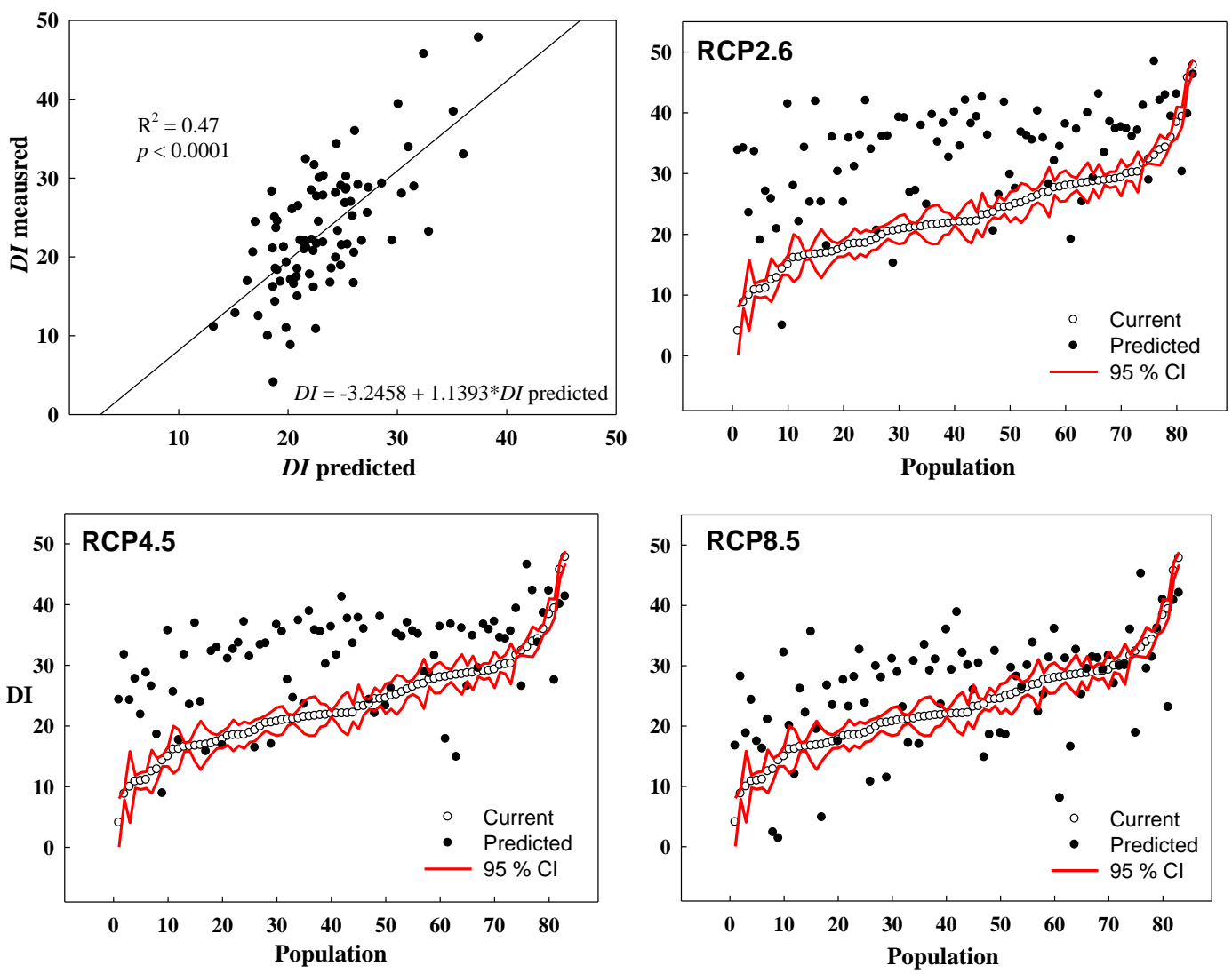

Figure 2. Seed dormancy (DI) prediction in 2050s. (a) Linear relationship between predicted DI and DI used for the correction of predicted seed dormancy; (b) corrected seed dormancy prediction using representative concentration pathways (RCP) 2.6, 4.5 and 8.5 , respectively. Note: (1) model for seed dormancy prediction, DI $=(2.4819+$ ecosystem zone $)+2.7079 \times$ Eref07 $-0.9284 \times$ Eref_summer + $6.6170 \times$ DD_O_summer [refer to Table S2 for intercept adjustment in each ecosystem zone]; (2) the population was ranked as per its current DI in ascending order and $95 \%$ confidence interval (CI) was plotted.

contrast, the PCA analysis showed several temperature-based variables which were intrinsically correlated (Fig. S5). In addition, the PLS analyses classified the 83 population habitats into 21 and 20 major categories for seed dormancy and weight, respectively (blue arrows in Fig. S4).

The first canonical correlation analysis (CCA) was significant across all statistical tests (Table S2a). Seed dormancy and weight had moderate $(0.66)$ and very strong $(0.90)$ correlations with climate, moderate $(0.59)$ and high $(0.74)$ correlations with life-history traits (i.e., combination of seed dormancy and weight), and moderate (0.53-0.55) correlation with geographic variables (Table 1a). This implies that the climatic variables were more important than the geographic variables in variations of life-history traits. Based on respective covariate matrices for "life-history traits", "climatic ecology", and "geographic ecology" canonical variates, 62.35 and $47.11,62.85$ and 45.06, 14.80 and $6.82 \%$ of variance were explained by their corresponding canonical variates for the same group of variables and the other group of variables (Table 1b). Furthermore, multivariate analyses showed that ecosystem zones were significant for seed dormancy and weight, and had moderate correlation $\left(R^{2}=0.55-0.56, P<0.0001\right)$ with life-history traits (Table 2).

In the hierarchical model for seed dormancy using climatic variables, the climatic variables Eref07, Eref_summer, and DD_O_summer were significant (Table $3 \mathrm{a}$ ). This indicates that summer moisture and temperature, the period corresponding to the plant-to-seed transition, played an important role in the development of seed dormancy. The intercept including error from ecosystem zones was not significant (Table 3a). For seed weight, variables PPTO7 and PPT10, Tmax07, and intercept were significant (Table 3b), indicating that July temperature and precipitation and October precipitation were important to seed weight. Ecosystem zones, representing ecological boundaries in geography, had a greater impact on the variation of seed weight than that of seed dormancy. In the geographic variable-based hierarchical model for seed dormancy, only longitude and intercept were significant (Table S4a and Fig. S6a). For seed weight, longitude, elevation and intercept were significant (Table S4b and Fig. S6b), indicating that longitude was an important geo- 
Table 1. Canonical correlation analysis between individual variables and their own and opposite set of variables.

\begin{tabular}{|c|c|c|c|c|}
\hline (a) & & & & \\
\hline \multicolumn{2}{|c|}{ Variables } & \multirow{2}{*}{$\begin{array}{r}\text { Life-history traits } \\
0.7429\end{array}$} & \multirow{2}{*}{$\frac{\text { Climatic ecology }^{1}}{0.9021}$} & \multirow{2}{*}{$\begin{array}{r}\text { Geographic ecology } \\
0.5481\end{array}$} \\
\hline Life-history & Seed weight & & & \\
\hline traits & DI & 0.5909 & 0.6582 & 0.5327 \\
\hline \multicolumn{5}{|l|}{ (b) } \\
\hline \multirow[t]{2}{*}{ Canonical variate } & \multicolumn{2}{|c|}{$\%$ explained variance by } & & \\
\hline & Their own & The opposite & & \\
\hline Life-history traits & $62.35 \%$ & $47.11 \%$ & & \\
\hline Climatic Ecology & $62.85 \%$ & $45.06 \%$ & & \\
\hline Geographic Ecology & $14.80 \%$ & $6.82 \%$ & & \\
\hline
\end{tabular}

graphic factor in life-history traits and geographic factors had greater influence on the variation of seed weight than seed dormancy. Considering all these results collectively, life-history traits were significantly influenced by precipitation as well as temperature in the plant-to-seed chronology, and roughly distributed in a longitude pattern.

\subsection{Prediction of life-history traits in response to climate change}

Using current climate data, seed dormancy predicted had a moderate linear relationship $\left(R^{2}=0.47, P<0.0001\right)$ with that observed (Fig. 2), which was used for the correction of the climate scenario predicted in 2050s. Seed dormancy predictions using three greenhouse gas emission scenarios (RCP2.6, 4.5, and 8.5) showed that DI in 2050s would increase (Fig. 2). In general, the spatial pattern of DI across the entire province showed that the seed dormancy in the south of B.C. would pronouncedly increase and the territory previously not suitable for pines to establish (grey area in 1970s) is expected to shrink in 2050 s, which are responses to climate change (Fig. 3). In addition, seed weight "predicted" had a low-moderate linear relationship $\left(R^{2}=0.34, P<0.0001\right)$ with observed values (Fig. S7).

\subsection{Correlated response in plasticity to timing of seed germination after "winter-chilling"}

Among the 83 lodgepole pine populations, variance of seed dormancy was significantly explained by genotype and environment (Table 2b). Estimate of broad-sense heritability $\left(\mathrm{H}^{2}\right)$ was 0.54 corresponding with the observed variance component for genotypes (Table $2 b$ ), indicating that genetic components have a moderate influence on seed dormancy variation. In response to significant $G \times E$ interaction (Table $2 b$ ), a plot of the reaction norms of AUC showed a range shift, nonparallelism, and crossing between moist-chilling and control (Fig. 4), where $G \times E$ accounted for $39 \%$ of the variance and was attributed to crossing of reaction norms (Table $2 b$ ), indicating that environments changed the adaptive values of the life-history trait.

AUC and phenotypic plasticity under chilling treatment had a moderate correlation $\left(R^{2}=0.53, P<0.0001\right.$; Fig. 4$)$, indicating that populations that germinated after chilling treatment were more plastic. However, when no treatment prior to germination was applied, AUC and plasticity yielded a weak and not statistically significant correlation ( $R^{2}=0.04, P=0.3479$; Fig. 4). Therefore, germination after the chilling treatment was able to increase the magnitude of phenotypic plasticity, which was a response to subsequent predictable environments.

\subsection{Expression of bet-hedge under manipulated environmental uncertainty}

Relative to "bad-year" simulation, "good-year" resulted in higher and uniform germination capacity and shorter time to germination across the 83 populations (Fig. 5). The standard deviation (SD) of germination capacity and time to germination were evenly distributed on the two sides of respective average line for both good- and bad-year across populations (Fig. 5) and "good-year" had lower average SD germination capacity and SD time to germination (Fig. 5). This indicates that, although bet-hedge is a risk strategy for unpredictable environments, "good-year" can lower the risk by means of allowing higher germination capacity and shorter time to germination across populations. 
Table 2. Multi- and uni-variate analyses for life-history traits. (a) MANOVA table reporting the correlation of seed dormancy (DI) and weight with ecosystems; (b) ANOVA table reporting significant effect of the genotype on phenotypic variance and associating broad-sense heritability $\left(H^{2}\right)$.

\begin{tabular}{|c|c|c|c|c|c|c|c|}
\hline \multirow[b]{3}{*}{ SOV } & \multicolumn{7}{|c|}{ Parameters } \\
\hline & \multirow[b]{2}{*}{$\mathrm{DF}$} & \multicolumn{3}{|c|}{ DI } & \multicolumn{3}{|c|}{ Seed weight } \\
\hline & & Mean squares & $F$ value & $R^{2}$ & Mean squares & $F$ value & $R^{2}$ \\
\hline Ecosystem zones & 21 & 130.3132 & $3.50^{*}$ & & 0.3011 & $3.63^{*}$ & \\
\hline corrected error & 61 & 37.1821 & & 0.55 & 0.0829 & & 0.56 \\
\hline \multicolumn{8}{|l|}{ (b) } \\
\hline SOV & DF & EMS & Mean squares & $F$ value & $\begin{array}{r}\text { Variance } \\
\text { components }\end{array}$ & $H^{2}$ & \\
\hline Genotype $(G)$ & 82 & $\sigma_{\varepsilon}^{2}+8 \sigma_{G}^{2}$ & 346.8691 & $67.01^{* *}$ & $54.02 \%$ & \multirow{4}{*}{0.54} & \\
\hline Environment $(E)$ & 1 & $\sigma_{\varepsilon}^{2}+4 \sigma_{G \times E}^{2}+332 \varphi_{E}$ & 89393.0625 & $17268.20^{* *}$ & - & & \\
\hline$G \times E$ & 82 & $\sigma_{\varepsilon}^{2}+4 \sigma_{G \times E}^{2}$ & 129.8935 & $25.09^{* *}$ & $39.43 \%$ & & \\
\hline Error $(\varepsilon)$ & 498 & $\sigma_{\varepsilon}^{2}$ & 5.1767 & & $6.55 \%$ & & \\
\hline
\end{tabular}

SOV: source of variation; DF: degrees of freedom; EMS: expected mean squares. - No variance components or percent of total variation were estimated for the fixed effect $(E){ }^{*} P<0.025$ ( $=0.05 / 2$ dependent variables). ${ }^{* *} P<0.05$.

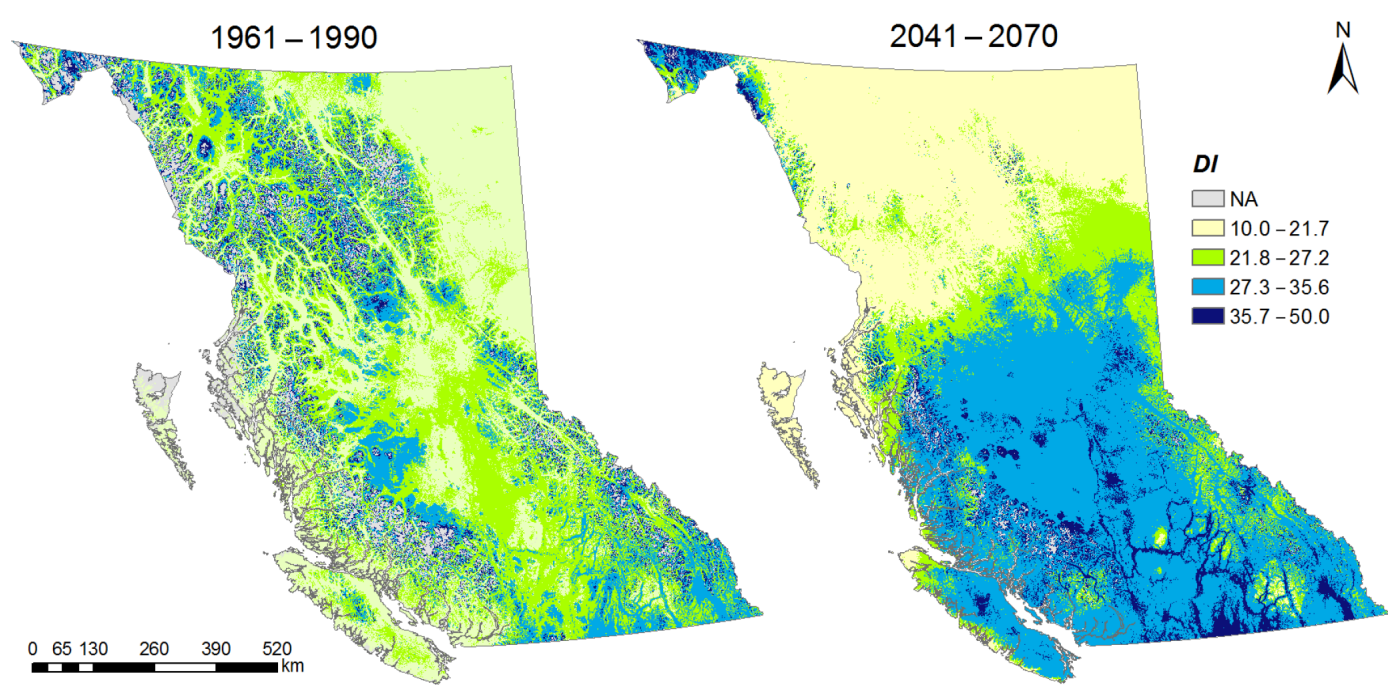

Figure 3. Map of predicted seed dormancy using climatic model for the reference period and 2050s in lodgepole pine across British Columbia. Note: DIs (i.e., dormancy indexes) are classified into five categories and represented by different colors on the map. The higher the value, the more dormant the seeds.

\section{Discussion}

Climate change is accelerating plant life-cycle transitions in coordination with the seasons. In life-cycle transitions, the environment plays a critical role in the development of lifehistory traits and in response to environmental stimuli, intrinsic mechanisms of genetics, epigenetics, phenotypic plasticity, bet-hedge strategy, and adaptive evolution take effect (Fig. 6). In this study, we found that seed dormancy and size were most correlated with evapotranspiration, precipi- tation and maximum mean temperature during the plant-toseed transition, respectively, using 83 lodgepole pine populations across British Columbia (B.C.), Canada. We predicted that the range of seed dormancy variation would increase across B.C. in 2050s. Moreover, winter-chilling can increase the magnitude of life-history plasticity (predictable factor) and lower the bet-hedge strategy (unpredictable factor). However, future climate may bring about insufficient winter-chilling required to decay seed dormancy, thus resulting in adverse consequences for the timing of phenology and 
(a)

(b)
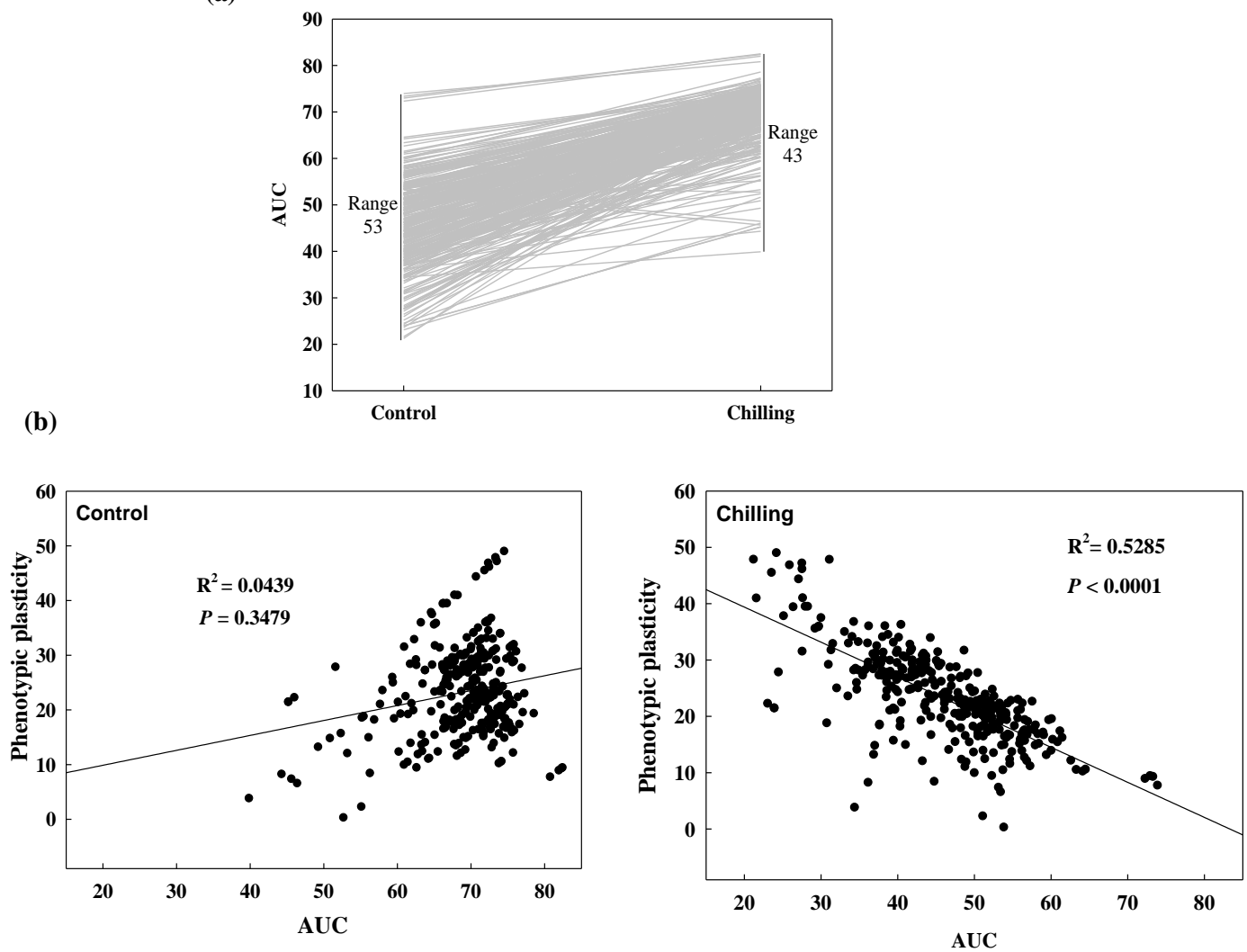

Figure 4. Studies of phenotypic plasticity. (a) Reaction norms for AUC with or without moist-chilling treatment across the 83 populations; (b) relationship between phenotypic plasticity and AUC with or without moist-chilling treatment. Best fit lines based on linear models are provided.

Table 3. Parameter estimates and statistical tests for the climatic variables-based hierarchical models regarding seed dormancy and weight; (a) seed dormancy model; (b) seed weight model.

\begin{tabular}{lrrrrr}
\hline (a) & & & & & \\
\hline Effect & Estimate & Standard Error & DF & Statistic & $P$ \\
\hline Intercept $^{1}\left(\beta_{0}\right)$ & 2.4819 & 7.9418 & 21 & $t=0.31$ & 0.7577 \\
Eref07 $\left(\beta_{1}\right)$ & 2.7076 & 0.8932 & 58 & $F=9.19$ & 0.0036 \\
Eref_summer $\left(\beta_{2}\right)$ & -0.9284 & 0.3354 & 58 & $F=7.66$ & 0.0076 \\
DD_0_summer $\left(\beta_{3}\right)$ & 6.5170 & 1.8480 & 58 & $F=9.06$ & 0.0039 \\
\hline (b) & & & & & \\
\hline Effect & Estimate & Standard Error & DF & Statistic & $P$ \\
\hline Intercept $^{1}\left(\beta_{0}\right)$ & 1.3290 & 0.3799 & 21 & $t=3.50$ & 0.0021 \\
$P P T 07\left(\beta_{1}\right)$ & 0.0046 & 0.0019 & 58 & $F=5.66$ & 0.0207 \\
$P P T 10\left(\beta_{2}\right)$ & -0.0014 & 0.0007 & 58 & $F=4.68$ & 0.0346 \\
Tmax07 $\left(\beta_{3}\right)$ & 0.0721 & 0.0150 & 58 & $F=23.11$ & $<0.0001$ \\
\hline
\end{tabular}

${ }^{1}$ Residual from the ecosystem zone $\left(\varepsilon_{j}\right)$ is integrated into "intercept" (Table S3).

the growth and establishment in lodgepole pine. This study allowed us to gain insights in the role of dynamic environments in shaping life-history characteristics.

\subsection{Environmental conditions in the plant-to-seed transition}

In the plant-to-seed chronology, the sexual reproduction of plants is vulnerable to climate change as influenced by the maternal environment (Hedhly et al., 2009; Donohue, 2009; Schmitt et al., 1992); and temperature is involved in both genetically based and environmentally induced parental effects (Lacey, 1996). Global warming has resulted in an upward shift in species optimum elevation and latitude (Chen et al., 2011; Lenoir et al., 2008; Parmesan and Yohe, 2003), an observation similar to that reported by Parmesan (2006) as she pointed out that the best places to seek potential changes in species ranges is at their altitudinal and latitudinal treelines (Parmesan, 2006). This suggested that climatic variables are the real causes of species' responses to environmental signals. Compared with the last 3 decades, the Pacific Northwest is expected to warm about $0.8-2.9^{\circ} \mathrm{C}$ by mid-century (Leung et al., 2004; Duffy et al., 2006; Mote et al., 2008), and 1.5$5.4^{\circ} \mathrm{C}$ by the end of the century (Mote et al., 2008). Warming in this region will be probably greater in summer $\left(3.9^{\circ} \mathrm{C}\right.$ on average) than in winter $\left(2.7^{\circ} \mathrm{C}\right.$; Mote et al., 2008). 

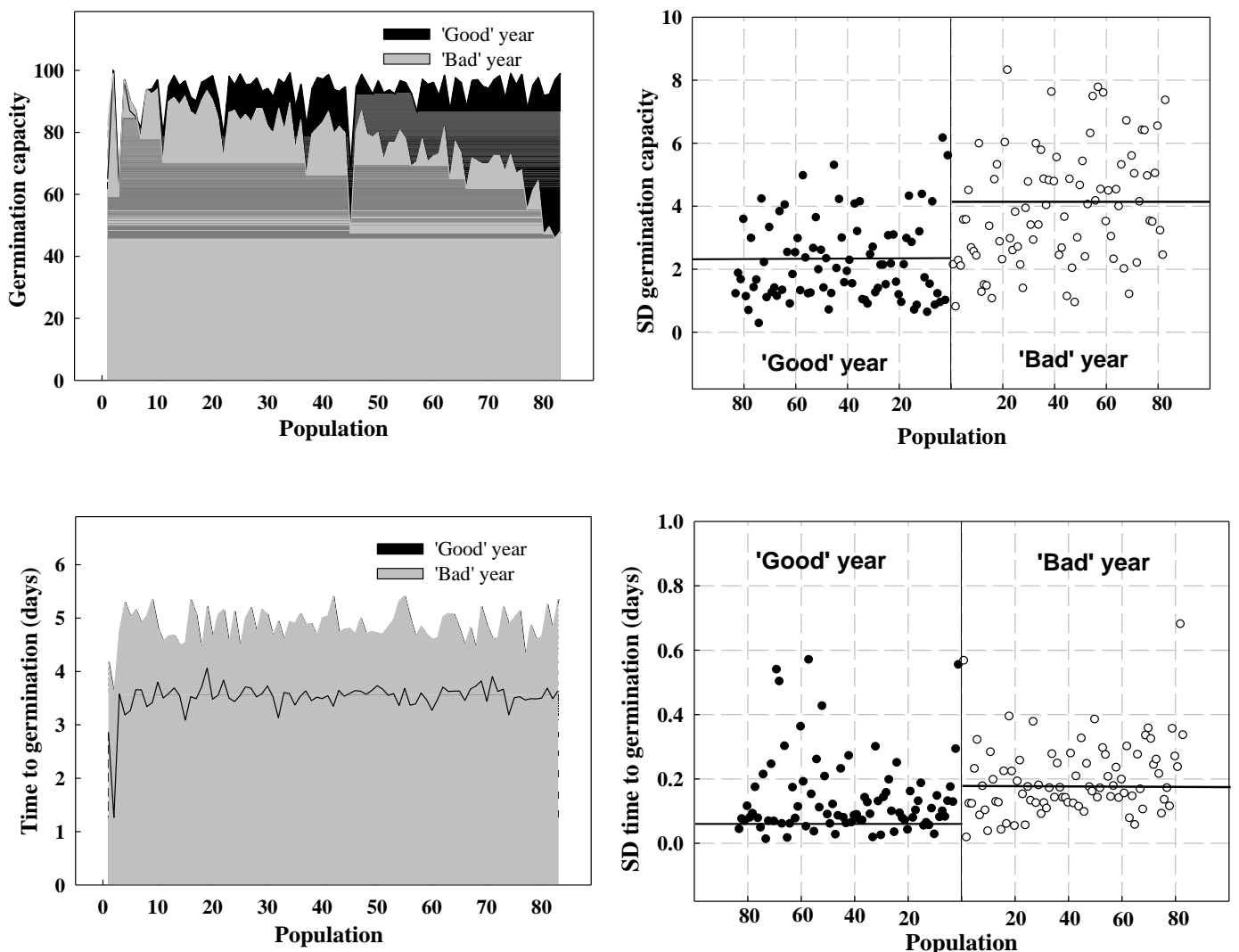

Figure 5. Studies of bet-hedge strategy. Bet-hedge dormancy involving germination capacity and time to germination (left) and their SD (right) in response to "good-year" and "bad-year" treatments. Note: the population was ranked as per its current DI in ascending order.

In the hierarchical model for seed dormancy, the climatic variable, summer degree-days below $0{ }^{\circ} \mathrm{C}\left(D D \_0 \_s u m m e r\right)$ was not equal to zero only for 16 out of the total 83 study populations and was projected to be zero for 80 populations in 2050s. We performed approximation by removing DD_0_summer from the model and the result of seed dormancy projection could be interpreted as the following: given the current-future difference in July hargreaves reference evaporation (Eref) is more than one third higher than that in summer Eref (June-August period), seed dormancy will increase in 2050s, and if such a difference is less than one third higher, seed dormancy will diminish. These results also suggest that the allocation of summer Eref in July (i.e., seed development period) was critical in the development of seed dormancy.

The ecosystem zones were significant in analyses of lifehistory traits using MANOVA (Table 2a) but not significant for seed dormancy and weight models (Table S2). This indicates that dynamic climatic variables are true driving effects on modulating life-history traits. On the other hand, gene flow as a single pollen grain carries half the number of alleles and may yield effective distance spanning from a few centimeters to thousands of kilometres (Nathan et al., 2008). The "abundant center" model, which deals with the spatial dis- tribution for populations across species' ranges and its evolutionary potential, also has implications (Volis et al., 2014; Etterson and Shaw, 2001; Parmesan, 2006), that is, compared with core populations, locally adapted peripheral populations had lower adaptive potential and were outperformed in the novel environment. Ecosystem zones like other geographic variables are not individual units to classify life-history traits.

A number of ecologically and evolutionary relevant genes have been identified in Arabidopsis and some annuals, such as FLC (Flowering Locus C), SCR/SP11 (S-locus CysteineRich protein/S-locus Protein 11; Shimizu et al., 2011; Amasino, 2010), as they provide genetic diversity in adaptive evolution. Moreover, both seed dormancy (genes in ABA and GA signalling circuit) and flowering (such as $F L C$ ) were modulated by epigenetic mechanisms (Müller et al., 2012; Chinnusamy et al., 2008; Bossdorf et al., 2008). This indicates that epigenetic changes play a significant role in evolution and ecology and the environment signals acting on genes by epigenetic modification were crucial for life-history traits. In recent years, much progress has been made in uncovering genes operating on different seed compartments i.e., embryo, endosperm, and seed coat, which modulate seed development (Le et al., 2010). Processes that regulate seed size and development are coordinated across several morphologically dis- 


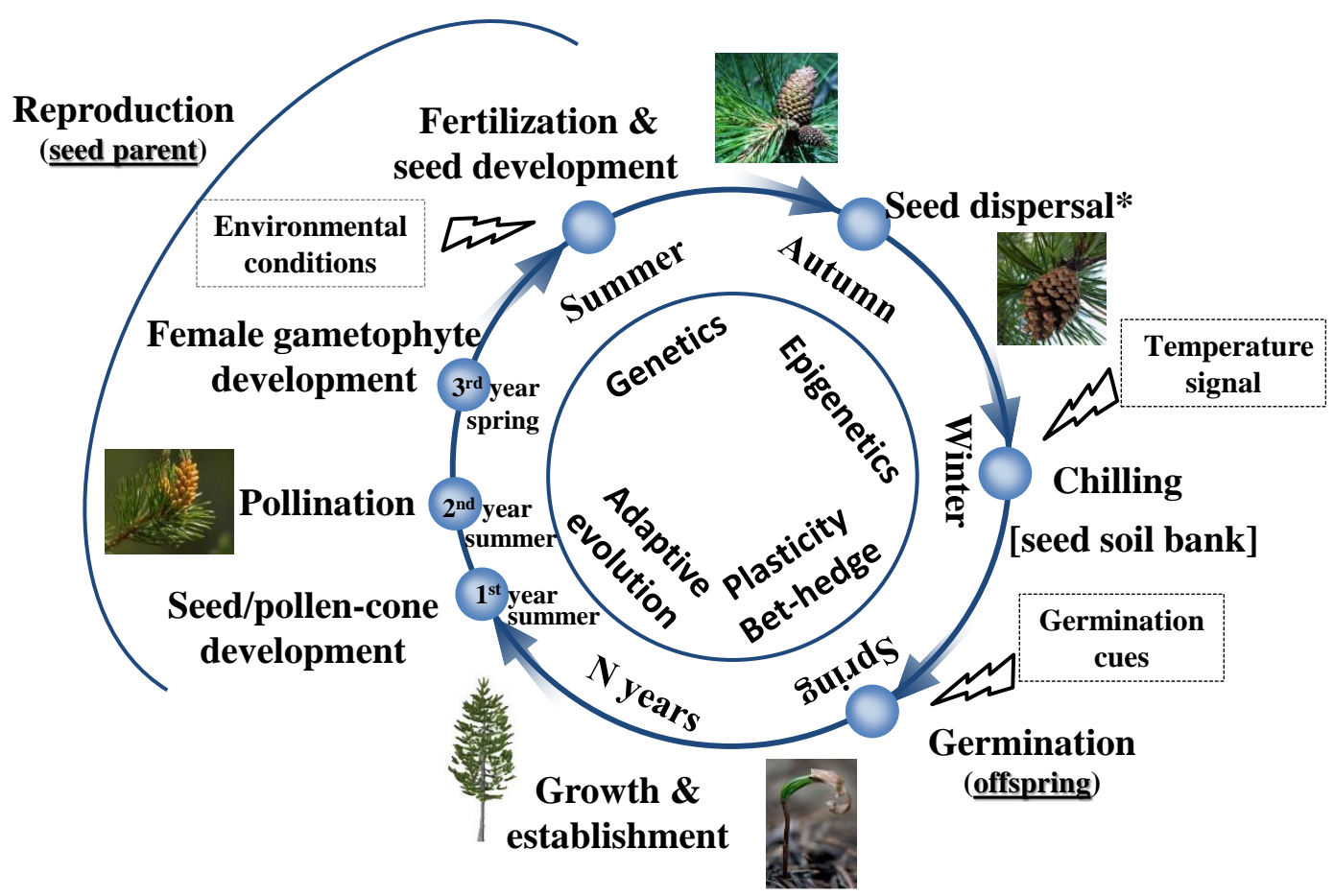

Figure 6. Important environment stages and intrinsic mechanisms in the life cycle of lodgepole pine for life-history traits. Note: (1) seed dispersal may not occur in the following season and it may take years until the cone drops and seeds release in nature; (2) the reproduction cycle of (lodgepole) pine undergoes 3 years, that is, seed/pollen cone initiation (August, September, October) $\rightarrow$ dormant (November, December, January, February, March) $\rightarrow$ pollen development (April, May) $\rightarrow$ pollination (June) $\rightarrow$ female gametophyte development (July, August) $\rightarrow$ dormant (September, October, November, December, January, February, March, April) $\rightarrow$ female gametophyte development (May, June).

tinct sub-regions (Belmonte et al., 2013) and the complex cross-talk and integration of signals from different components of the seed together determine its final size (Garcia et al., 2005).

\subsection{Temperature signals in winter-chilling}

Winter dormancy is an important adaptive strategy as it prevents plants from flushing during short warm periods in the winter. Winter chilling is an important environmental signal for plant life histories, which accelerates flowering through vernalization in winter annuals and alleviates both bud and seed dormancy, allowing the onset of growth in springs (Penfield, 2008; Penfield and Springthorpe, 2012). Seeds take advantage of environmental temperature as a key signal to coordinate timing of seed germination, allowing plants to synchronize their life histories with the seasons. Low temperature can promote dormancy at the inception of seed maturation, but promotes dormancy alleviation in mature seeds after imbibition. It is therefore assumed that chilling plays a dual role in regulating dormancy (Batlla and Benech-Arnold, 2010).

With substantial climate warming $\left(>3^{\circ} \mathrm{C}\right)$, chilling may be insufficient in many woody perennials, such as poplar, western hemlock, and Sitka spruce, resulting in delayed bud burst and poor growth (Cannell and Smith, 1986; Murray et al., 1989; Morin et al., 2009). Based on the three different RCP scenarios, we predicted that winter-chilling days (DD_0_winter) would on average decrease by $24 \%$ across the 83 study habitats in 2050s relative to present (Fig. S8, ranges also provided), which may lead to insufficient dormancy alleviation through winter-chilling. However, spring and annual heat sums (DD5_spring and DD5) would increase by 95 and $49 \%$, respectively, in 2050s (Fig. S8), resulting in earlier springs and advanced vegetative green-ups and an increase in growing season length (Robeson, 2004; Schwartz et al., 2006). In 2050s, inadequate winter-chilling may delay germination and an extended germination span leads to adverse conditions during dry summers. As such, future climate will change the timing of conifer phenology and may give rise to adverse consequences.

In terms of molecular mechanisms in alleviation of seed dormancy via winter-chilling, several studies demonstrated that moist-chilling involves changes in levels of ABA, GAs, and auxin, and transcripts in respective signaling cascades, GA3 oxidase 1, for example (Yamauchi et al., 2004; AliRachedi et al., 2004; X. D. Liu et al., 2013; Liu et al., 2015). 


\subsection{Germination cues in the seed-to-plant transition}

Changes in climate alter patterns of phenology and thus multiple life-history traits. In response to climate change, phenotypic plasticity associated with life-history traits (Pigliucci, 2001; Chevin et al., 2010; Franks et al., 2014; Liu and ElKassaby, 2015) and genetically based trait responses (Bradshaw and Holzapfel, 2001, 2008; Thompson et al., 2013) were well documented. In the long run, only the species that can respond by phenotypic plasticity and/or genetically based local adaptation can persist (Jump and Penuelas, 2005). However, the evolutionary response to climate change may be attenuated due to constraints causing a time lag between the environmental change and an observed evolutionary response (Etterson and Shaw, 2001; Davis et al., 2005). In tree populations, the extent of the constraints will hinge on phenotypic variation, strength of selection, fecundity, interspecific competition, and biotic interaction (Aitken et al., 2008).

Differences in plasticity exist among populations, but plasticity presumed to be adaptive may often be neutral or maladaptive (Caruso et al., 2006). An optimal balance between adaptive and non-adaptive (bet-hedging) plasticity may exist and possibly vary among populations. Moreover, germination characters are expected to exhibit phenotypic plasticity to environmental variables experienced not only by seed following dispersal but also by seed parents prior to dispersal (Schmitt et al., 1992).

It is noteworthy that seed dormancy and germination is a quantitative trait that interacts with environment factors (Bentsink et al., 2007). Some QTLs associated with germination phenology in Arabidopsis can attain allele frequencies approaching fixation within a single generation even though they started with frequencies below $50 \%$ (Huang et al., 2010), indicating strong directional selection. Seed dormancy in Arabidopsis was associated with a cohort of genes controlled by seasonally distinct hormone-signalling pathways in the seed soil bank, such as DOG1 (Delay Of Germination 1), MFT (Mother of Flowering Timing), DELLAs (repressors of germination potential and GA signalling), and PIFs (Phytochrome Interacting Factors; Footitt et al., 2011, 2014). In addition, photoperiod can affect seed dormancy and germination and phytochromes were the most investigated photoreceptors. Phytochromes are temperature- and light-dependent in association with GA pathway via the bHLH transcription factor SPATULA (SPT; Heschel et al., 2007). SPT is a light-stable repressor of seed germination and mediates the germination response to temperature through temperature-sensitive changes in its transcription (Penfield et al., 2005).

In summary, we reinforced the importance of climatic signals during seed set to the formation of early life-history traits (i.e., seed dormancy and size). Variations of life-history traits may be acquired through signal transduction cascades and/or gene/protein imprintings triggered by specific envi- ronmental variables, such as evapotranspiration and precipitation. The period of winter chilling exerts a pronounced influence on the range of life-history plasticity and the variation of bet-hedge strategy when the life-history trait expressed (i.e., seed emergence). In response to previous memory during seed development and different genetic architectures that every individual harbors, germination behaviour (e.g., timing of seed germination) varies even given the same optimal germination cues.

\section{The Supplement related to this article is available online at doi:10.5194/bg-13-2945-2016-supplement.}

Author contributions. Yang Liu conceived the study, carried out data analysis, and drafted the manuscript; Tongli Wang participated in selection of study populations, performed current and future climate predictions and mapping, and commented on the manuscript; and Yousry A. El-Kassaby coordinated the study and helped draft the manuscript. All authors gave final approval for publication.

Acknowledgements. We are grateful to D. Kolotelo for seed supply and to O. El-Kassaby for technical assistance. We are also thankful to the editors and anonymous referees for their constructive comments.

This work was supported by the Johnson's Family Forest Biotechnology Endowment and the National Science and Engineering Research Council of Canada Discovery and Industrial Research Chair to ousry A. El-Kassaby.

Edited by: K. Thonicke

\section{References}

Abdi, H.: Partial least square regression Encyclopedia of measurement and statistics, edited by: Salkind, N. J., Sage Publications, Inc., Thousand Oaks, CA/London/New Dehli, 2007.

Adler, P. B., Salguero-Gómez, R., Compagnoni, A., Hsu, J. S. Ray-Mukherjee, J., Mbeau-Ache, C., and Franco, M.: Functional traits explain variation in plant life history strategies, P. Natl. Acad. Sci. USA, 111, 740-745, doi:10.1073/pnas.1315179111, 2014.

Aitken, S. N., Yeaman, S., Holliday, J. A., Wang, T. L., and Curtis-McLane, S.: Adaptation, migration or extirpation: climate change outcomes for tree populations, Evol. Appl., 1, 95-111, doi:10.1111/j.1752-4571.2007.00013.x, 2008.

Ali-Rachedi, S., Bouinot, D., Wagner, M. H., Bonnet, M., Sotta, B., Grappin, P., and Jullien, M.: Changes in endogenous abscisic acid levels during dormancy release and maintenance of mature seeds: studies with the Cape Verde Islands ecotype, the dormant model of Arabidopsis thaliana, Planta, 219, 479-488, doi:10.1007/s00425-004-1251-4, 2004. 
Amasino, R.: Seasonal and developmental timing of flowering, Plant J., 61, 1001-1013, doi:10.1111/j.1365313X.2010.04148.x, 2010.

Baskin, C. C. and Baskin, M. J.: Seeds: ecology, biogeography, and evolution of dormancy and germination Academic Press, San Diego, California, 666 pp., 1998.

Batlla, D. and Benech-Arnold, R. L.: Predicting changes in dormancy level in natural seed soil banks, Plant Mol. Biol., 73, 3-13, doi:10.1007/s11103-010-9601-z, 2010.

Belmonte, M. F., Kirkbride, R. C., Stone, S. L., Pelletier, J. M., Bui, A. Q., Yeung, E. C., Hashimoto, M., Fei, J., Harada, C. M., Munoz, M. D., Le, B. H., Drews, G. N., Brady, S. M., Goldberg, R. B., and Harada, J. J.: Comprehensive developmental profiles of gene activity in regions and subregions of the Arabidopsis seed, P. Natl. Acad. Sci. USA, 110, E435-E444, doi:10.1073/pnas.1222061110, 2013.

Bentsink, L., Soppe, W., and Koornneef, M.: Genetic aspects of seed dormancy, in: Seed development, dormancy and germination, Blackwell publishing Ltd Oxford, UK, 2007.

Bossdorf, O., Richards, C. L., and Pigliucci, M.: Epigenetics for ecologists, Ecol. Lett., 11, 106-115, doi:10.1111/j.14610248.2007.01130.x, 2008.

Bradshaw, W. E. and Holzapfel, C. M.: Genetic shift in photoperiodic response correlated with global warming, P. Natl. Acad. Sci. USA, 98, 14509-14511, doi:10.1073/pnas.241391498, 2001.

Bradshaw, W. E. and Holzapfel, C. M.: Genetic response to rapid climate change: it's seasonal timing that matters, Mol. Ecol., 17, 157-166, doi:10.1111/j.1365-294X.2007.03509.x, 2008.

Breshears, D. D., Huxman, T. E., Adams, H. D., Zou, C. B., and Davison, J. E.: Vegetation synchronously leans upslope as climate warms, P. Natl. Acad. Sci. USA, 105, 11591-11592, doi:10.1073/pnas.0806579105, 2008.

Calow, P.: The encyclopedia of ecology and environmental management, Blackwell Science, New York, 1998.

Cannell, M. G. R. and Smith, R. I.: Climatic Warming, spring budburst and frost damage on trees, J. Appl. Ecol., 23, 177-191, doi:10.2307/2403090, 1986.

Carrascal, L. M., Galvan, I., and Gordo, O.: Partial least squares regression as an alternative to current regression methods used in ecology, Oikos, 118, 681-690, doi:10.1111/j.16000706.2008.16881.x, 2009.

Caruso, C. M., Maherali, H., and Sherrard, M.: Plasticity of physiology in Lobelia: testing for adaptation and constraint, Evolution, 60, 980-990, 2006.

Chen, I. C., Hill, J. K., Ohlemüller, R., Roy, D. B., and Thomas, C. D.: Rapid range shifts of species associated with high levels of climate warming, Science, 333, 1024-1026, doi:10.1126/science.1206432, 2011.

Chevin, L. M., Lande, R., and Mace, G. M.: Adaptation, plasticity, and extinction in a changing environment: Towards a predictive theory, PLoS Biol., 8, e1000357, doi:10.1371/journal.pbio.1000357, 2010.

Childs, D. Z., Metcalf, C. J., and Rees, M.: Evolutionary bethedging in the real world: empirical evidence and challenges revealed by plants, P. Roy. Soc. B, 277, 3055-3064, doi:10.1098/rspb.2010.0707, 2010.

Chinnusamy, V., Gong, Z. Z., and Zhu, J. K.: Abscisic acidmediated epigenetic processes in plant development and stress responses, J. Integr. Plant. Biol., 50, 1187-1195, 2008.
Cleland, E. E., Chuine, I., Menzel, A., Mooney, H. A., and Schwartz, M. D.: Shifting plant phenology in response to global change, Trends Ecol. Evol., 22, 357-365, 2007.

Cohen, D.: Optimizing reproduction in a randomly varying environment, J. Theor. Biol., 12, 119-129, 1966.

Crossa, J., Vargas, M., Cossani, C. M., Alvarado, G., Burgueño, J., Mathews, K. L., and Reynolds, M. P.: Evaluation and interpretation of interactions, Agron. J., 105, 1-12, 2013.

Davis, M. B., Shaw, R. G., and Etterson, J. R.: Evolutionary responses to changing climate, Ecology, 86, 1704-1714, doi:10.1890/03-0788, 2005.

Donohue, K.: Completing the cycle: maternal effects as the missing link in plant life histories, Philos. T. R. Soc. B, 364, 1059-1074, doi:10.1098/rstb.2008.0291, 2009.

Donohue, K., de Casas, R. R., Burghardt, L., Kovach, K., and Willis, C. G.: Germination, postgermination adaptation, and species ecological ranges, Annu. Rev. Ecol. Evol. S., 41, 293 319, doi:10.1146/annurev-ecolsys-102209-144715, 2010.

Duffy, P. B., Arritt, R. W., Coquard, J., Gutowski, W., Han, J., Iorio, J., Kim, J., Leung, L. R., Roads, J., and Zeledon, E.: Simulations of present and future climates in the western United States with four nested regional climate models, J. Climate, 19, 873-895, doi:10.1175/Jcli3669.1, 2006.

El-Kassaby, Y. A., Moss, I., Kolotelo, D., and Stoehr, M.: Seed germination: Mathematical representation and parameters extraction, Forest Sci., 54, 220-227, 2008.

Eriksson, O., Friis, E. M., and Löfgren, P.: Seed size, fruit size, and dispersal systems in angiosperms from the Early Cretaceous to the Late Tertiary, Am. Nat., 156, 47-58, doi:10.1086/303367, 2000.

Etterson, J. R. and Shaw, R. G.: Constraint to adaptive evolution in response to global warming, Science, 294, 151-154, doi:10.1126/science.1063656, 2001.

Finch-Savage, W. E. and Leubner-Metzger, G.: Seed dormancy and the control of germination, New Phytol., 171, 501-523, 2006.

Footitt, S., Douterelo-Soler, I., Clay, H., and Finch-Savage, W. E.: Dormancy cycling in Arabidopsis seeds is controlled by seasonally distinct hormone-signaling pathways, P. Natl. Acad. Sci. USA, 108, 20236-20241, doi:10.1073/pnas.1116325108, 2011.

Footitt, S., Clay, H. A., Dent, K., and Finch-Savage, W. E.: Environment sensing in spring-dispersed seeds of a winter annual Arabidopsis influences the regulation of dormancy to align germination potential with seasonal changes, New Phytol., 202, 929-939, doi:10.1111/nph.12694, 2014.

Forbis, T. A., Floyd, S. K., and de Queiroz, A.: The evolution of embryo size in angiosperms and other seed plants: Implications for the evolution of seed dormancy, Evolution, 56, 2112-2125, 2002.

Fowells, H. A.: Silvics of forest trees of the United States, Agric. Handb. US Dep. Agric., Washington D.C., 762 pp., 1965.

Franks, S. J., Weber, J. J., and Aitken, S. N.: Evolutionary and plastic responses to climate change in terrestrial plant populations, Evol. Appl., 7, 123-139, doi:10.1111/Eva.12112, 2014.

Garcia, D., Fitz Gerald, J. N., and Berger, F.: Maternal control of integument cell elongation and zygotic control of endosperm growth are coordinated to determine seed size in Arabidopsis, Plant Cell, 17, 52-60, doi:10.1105/tpc.104.027136, 2005. 
Gillespie, J.: Natural selection for variances in offspring numbers: a new evolutionary priciple, Am. Nat., 111, 1010-1014, doi:10.1086/283230, 1977.

Hedhly, A., Hormaza, J. I., and Herrero, M.: Global warming and sexual plant reproduction, Trends Plant Sci., 14, 30-36, doi:10.1016/j.tplants.2008.11.001, 2009.

Heschel, M. S., Selby, J., Butler, C., Whitelam, G. C., Sharrock, R. A., and Donohue, K.: A new role for phytochromes in temperature-dependent germination, New Phytol., 174, 735-741, doi:10.1111/j.1469-8137.2007.02044.x, 2007.

Huang, X. Q., Schmitt, J., Dorn, L., Griffith, C., Effgen, S., Takao, S., Koornneef, M., and Donohue, K.: The earliest stages of adaptation in an experimental plant population: strong selection on QTLS for seed dormancy, Mol. Ecol., 19, 1335-1351, doi:10.1111/j.1365-294X.2010.04557.x, 2010.

Johnsen, Ø. and Skrøppa, T.: Adaptive properties of Picea abies progenies are influenced by environmental signals during sexual reproduction, Euphytica, 92, 67-71, 1996.

Jump, A. S. and Penuelas, J.: Running to stand still: adaptation and the response of plants to rapid climate change, Ecol. Lett., 8, 1010-1020, doi:10.1111/j.1461-0248.2005.00796.x, 2005.

Jump, A. S., Marchant, R., and Peñuelas, J.: Environmental change and the option value of genetic diversity, Trends Plant Sci., 14, 51-58, 2009.

Lacey, E. P.: Parental effects in Plantago lanceolata L.I., A growth chamber experiment to examine pre- and postzygotic temperature effects, Evolution, 50, 865-878, 1996.

Lande, R. and Shannon, S.: The role of genetic variation in adaptation and population persistence in a changing environment, Evolution, 50, 434-437, 1996.

Le, B. H., Cheng, C., Bui, A. Q., Wagmaister, J. A., Henry, K. F., Pelletier, J., Kwong, L., Belmonte, M., Kirkbride, R., Horvath, S., Drews, G. N., Fischer, R. L., Okamuro, J. K., Harada, J. J., and Goldberg, R. B.: Global analysis of gene activity during Arabidopsis seed development and identification of seed-specific transcription factors, P. Natl. Acad. Sci. USA, 107, 8063-8070, doi:10.1073/pnas.1003530107, 2010.

Lenoir, J., Gegout, J. C., Marquet, P. A., de Ruffray, P., and Brisse, H.: A significant upward shift in plant species optimum elevation during the 20th century, Science, 320, 1768-1771, doi:10.1126/science.1156831, 2008.

Leung, L. R., Qian, Y., Bian, X. D., Washington, W. M., Han, J. G., and Roads, J. O.: Mid-century ensemble regional climate change scenarios for the western United States, Climatic Change, 62, 75-113, doi:10.1023/B:Clim.0000013692.50640.55, 2004.

Liu, X. D., Zhang, H., Zhao, Y., Feng, Z. Y., Li, Q., Yang, H. Q., Luan, S., Li, J. M., and He, Z. H.: Auxin controls seed dormancy through stimulation of abscisic acid signaling by inducing ARFmediated ABI3 activation in Arabidopsis, P. Natl. Acad. Sci. USA, 110, 15485-15490, doi:10.1073/pnas.1304651110, 2013.

Liu, Y. and El-Kassaby, Y.: Timing of seed germination correlated with temperature-based environmental conditions during seed development in conifers, Seed Sci. Res., 25, 29-45, doi:10.1017/S0960258514000361, 2015.

Liu, Y., Kermode, A. R., and El-Kassaby, Y. A.: The role of moistchilling and thermo-priming on the germination characteristics of white spruce (Picea glauca) seed, Seed Sci. Technol., 41, 321335,2013
Liu, Y., Müller, K., El-Kassaby, Y. A., and Kermode, A. R.: Changes in hormone flux and signaling in white spruce (Picea glauca) seeds during the transition from dormancy to germination in response to temperature cues, BMC Plant Biol., 15, 292, doi:10.1186/s12870-015-0638-7, 2015.

Manly, B. F. J.: Multivariate statistical methods: A primer, 3rd Edn., Chapman and Hall/CRC, Boca Raton, Florida, 2005.

Morin, X., Lechowicz, M. J., Augspurger, C., O’ Keefe, J., Viner, D., and Chuine, I.: Leaf phenology in 22 North American tree species during the 21st century, Glob. Change Biol., 15, 961975, doi:10.1111/j.1365-2486.2008.01735.x, 2009.

Mote, P., Salathé, E., Dulière, V., and Jump, E.: Scenarios of future climate for the Pacific Northwest, University of Washington, Seattle, WA, 2008.

Müller, K., Bouyer, D., Schnittger, A., and Kermode, A. R.: Evolutionarily conserved histone methylation dynamics during seed life-cycle transitions, PloS One, 7, e51532, doi:10.1371/journal.pone.0051532, 2012.

Murray, M. B., Cannell, M. G. R., and Smith, R. I.: Date of budburst of 15 tree species in Britain following climatic warming, J. Appl. Ecol., 26, 693-700, doi:10.2307/2404093, 1989.

Nathan, R., Schurr, F. M., Spiegel, O., Steinitz, O., Trakhtenbrot, A., and Tsoar, A.: Mechanisms of long-distance seed dispersal, Trends Ecol. Evol., 23, 638-647, doi:10.1016/j.tree.2008.08.003, 2008.

Owens, J. N., Simpson, S. J., and Molder, M.: Sexual reproduction of Pinus Contorta, I. Pollen development, the pollination mechanism, and early ovule development, Can. J. Bot., 59, 1828-1843, 1981.

Owens, J. N., Simpson, S. J., and Molder, M.: Sexual reproduction of Pinus Contorta, II. Postdormancy ovule, embryo, and seed development, Can. J. Bot., 60, 2071-2083, 1982.

Parmesan, C.: Ecological and evolutionary responses to recent climate change, Annu. Rev. Ecol. Evol. S., 37, 637-669, doi:10.1146/annurev.ecolsys.37.091305.110100, 2006.

Parmesan, C. and Yohe, G.: A globally coherent fingerprint of climate change impacts across natural systems, Nature, 421, 37-42, 2003.

Penfield, S.: Temperature perception and signal transduction in plants, New Phytol., 179, 615-628, doi:10.1111/j.14698137.2008.02478.x, 2008.

Penfield, S. and Springthorpe, V.: Understanding chilling responses in Arabidopsis seeds and their contribution to life history, Philos. T. R. Soc. B, 367, 291-297, doi:10.1098/rstb.2011.0186, 2012.

Penfield, S., Josse, E. M., Kannangara, R., Gilday, A. D., Halliday, K. J., and Graham, I. A.: Cold and light control seed germination through the bHLH transcription factor SPATULA, Curr. Biol., 15, 1998-2006, doi:10.1016/j.cub.2005.11.010, 2005.

Pigliucci, M.: Phenotypic plasticity: Beyond nature and nurture, Johns Hopkins University Press, Maryland, 2001.

Plomion, C., Chagné, D., Pot, D., Kumar, S., Wilcox, P. L., Burdon, R. D., Prat, D., Peterson, D. G., Paiva, J., Chaumeil, P., Vendramin, G. G., Sebastiani, F., Nelson, C. D., Echt, C. S., Savolainen, O., Kubisiak, T. L., Cervera, M. T., de María, N., and Islam-Faridi, M. N.: Pines, Forest Trees, 7, 29-92, 2007.

Pourrat, Y. and Jacques, R.: The influence of photoperiodic conditions received by the mother plant on morphological and physiological characteristics of Chenopodium polyspermum L. seeds, Plant Sci. Lett., 4, 273-279, 1975. 
Raudenbush, S. W. and Bryk, A. S.: Hierarchical linear models: applications and data analysis methods (2nd Edn.), SAGE Publications, Inc., CA, 2001.

Robeson, S. M.: Trends in time-varying percentiles of daily minimum and maximum temperature over North America, Geophys. Res. Lett., 31, 1-4, 2004.

Schmitt, J., Niles, J., and Wulff, R.: Norms of reaction of seed traits to maternal environments in Plantago lanceolata, Am. Nat., 139, 451-466, 1992.

Schwartz, M. D., Ahas, R., and Aasa, A.: Onset of spring starting earlier across the Northern Hemisphere, Glob. Change Biol., 12, 343-351, 2006.

Shimizu, K. K., Kudoh, H., and Kobayashi, M. J.: Plant sexual reproduction during climate change: gene function in natura studied by ecological and evolutionary systems biology, Ann. Bot., 108, 777-787, doi:10.1093/Aob/Mcr180, 2011.

Simons, A. M.: Fluctuating natural selection accounts for the evolution of diversification bet hedging, P. Roy. Soc. B, 276, 19871992, doi:10.1098/rspb.2008.1920, 2009.

Simons, A. M.: Playing smart vs. playing safe: the joint expression of phenotypic plasticity and potential bet hedging across and within thermal environments, J. Evol. Biol., 27, 1047-1056, doi:10.1111/jeb.12378, 2014.

Skrøppa, T., Tollefsrud, M. M., Sperisen, C., and Johnsen, Ø.: Rapid change in adaptive performance from one generation to the next in Picea abies - Central European trees in a Nordic environment, Tree Genet. Genomes, 6, 93-99, doi:10.1007/s11295-009-0231z, 2010.

Slatkin, M.: Hedging ones evolutionary bets, Nature, 250, 704-705, doi:10.1038/250704b0, 1974.

Stocker, T. F., Qin, D., Plattner, G.-K., Alexander, L. V., Allen, S. K., Bindoff, N. L., Bréon, F.-M., Church, J. A., Cubasch, U., Emori, S., Forster, P., Friedlingstein, P., Gillett, N., Gregory, J. M., Hartmann, D. L., Jansen, E., Kirtman, B., Knutti, R., Krishna Kumar, K., Lemke, P., Marotzke, J., Masson-Delmotte, V., Meehl, G. A., Mokhov, I. I., Piao, S., Ramaswamy, V., Randall, D., Rhein, M., Rojas, M., Sabine, C., Shindell, D., Talley, L. D., Vaughan, D. G., and Xie, S.-P.: Technical summary, in: Climate change 2013: The physical science basis. Contribution of working group I to the Fifth Assessment Report of the Intergovernmental Panel on Climate Change, edited by: Stocker, T. F., Qin, D., Plattner, G.-K., Tignor, M., Allen, S. K., Boschung, J., Nauels, A., Xia, Y., Bex, V., and Midgley, P. M., Cambridge University Press, Cambridge, United Kingdom and New York, NY, USA, 33-115, 2013.

Tabachnick, B. G. and Fidell, L. S.: Using Multivariate Statistics, 6th Edn., Pearson Education, Boston, 2012.

Thompson, J., Charpentier, A., Bouguet, G., Charmasson, F., Roset, S., Buatois, B., Vernet, P., and Gouyon, P. H.: Evolution of a genetic polymorphism with climate change in a Mediterranean landscape, P. Natl. Acad. Sci. USA, 110, 2893-2897, doi:10.1073/pnas.1215833110, 2013.
Venable, D. L. and Brown, J. S.: The selective interactions of dispersal, dormancy, and seed size as adaptations for reducing risk in variable environments, Am. Nat., 131, 360-384, doi:10.1086/284795, 1988.

Volis, S., Ormanbekova, D., Yermekbayev, K., Song, M., and Shulgina, I.: Introduction beyond a species range: a relationship between population origin, adaptive potential and plant performance, Heredity, 113, 268-276, doi:10.1038/hdy.2014.25, 2014.

Walck, J. L., Hidayati, S. N., Dixon, K. W., Thompson, K., and Poschlod, P.: Climate change and plant regeneration from seed, Glob. Change Biol., 17, 2145-2161, 2011.

Walter, H. and Breckle, S. W.: Walter's vegetation of the earth: the ecological systems of the geo-biosphere, 4th Edn., Springer Berlin, 2002.

Walther, G. R., Post, E., Convey, P., Menzel, A., Parmesan, C., Beebee, T. J. C., Fromentin, J. M., Hoegh-Guldberg, O., and Bairlein, F.: Ecological responses to recent climate change, Nature, 416, 389-395, 2002.

Wang, T., Hamann, A., Yanchuk, A., O’Neill, G. A., and Aitken, S. N.: Use of response functions in selecting lodgepole pine populations for future climates, Glob. Change Biol., 12, 2404-2416, doi:10.1111/j.1365-2486.2006.01271.x, 2006.

Wang, T. L., Hamann, A., Spittlehouse, D. L., and Murdock, T. Q.: ClimateWNA - High-resolution spatial climate data for western North America, J. Appl. Meteorol. Clim., 51, 16-29, doi:10.1175/Jamc-D-11-043.1, 2012.

Waring, R. H. and Franklin, J. F.: Evergreen coniferous forests of the pacific northwest, Science, 204, 1380-1386, doi:10.1126/science.204.4400.1380, 1979.

West, B. T., Welch, K. B., and T., G. A.: Linear mixed models: a practical guide using statistical software, Chapman and Hall/CRC, New York, 2007.

Woodward, F. I. and Williams, B. G.: Climate and plant distribution at global and local scales, Vegetatio, 69, 189-197, 1987.

Yakovlev, I., Fossdal, C. G., Skrøppa, T., Olsen, J. E., Jahren, A. H., and Johnsen, $\varnothing .:$ An adaptive epigenetic memory in conifers with important implications for seed production, Seed Sci. Res., 22, 63-76, 2012.

Yamauchi, Y., Ogawa, M., Kuwahara, A., Hanada, A., Kamiya, Y., and Yamaguchi, S.: Activation of Gibberellin biosynthesis and response pathways by low temperature during imbibition of Arabidopsis thaliana seeds, Plant Cell, 16, 367-378, doi:10.1105/Tpc.018143, 2004.

Yan, W. and Tinker, N. A.: Biplot analysis of multi-environment trial data: Principles and applications, Can. J. Plant. Sci., 86, 623-645, 2006.

Yan, W. K.: GGEbiplot - A windows application for graphical analysis of multienvironment trial data and other types of two-way data, Agron. J., 93, 1111-1118, 2001. 